\title{
Correlation between femorotibial pressure and joint gap in osteoarthritis patients with varus deformity: an intraoperative measurement using sensor device in primary posterior-stabilized total knee arthroplasty
}

\author{
Xing Li, Hong Cai, Zhenguo Yu, Zijian Li, Ke Zhang, Hua Tian, Zhongjun Liu \\ Department of Orthopedics, Peking University Third Hospital, Beijing, China \\ Contributions: (I) Conception and design: H Cai, X Li; (II) Administrative support: Z Liu, H Cai, K Zhang; (III) Provision of study materials or \\ patients: H Cai, H Tian, Z Li; (IV) Collection and assembly of data: All authors; (V) Data analysis and interpretation: X Li, Z Yu; (VI) Manuscript \\ writing: All authors; (VII) Final approval of manuscript: All authors. \\ Correspondence to: Hong Cai, MD. Department of Orthopedics, Peking University Third Hospital, No. 49 North Garden Road, Haidian District, \\ Beijing 100191, China. Email: hongcai@bjmu.edu.cn.
}

\begin{abstract}
Background: The normal femorotibial pressure and its variation under different gap values remain unknown. Thus, for the purpose of improving soft-tissue balancing in total knee arthroplasty (TKA), a loadsensor device was used to measure femorotibial pressures. More specifically, the aim of this study was to analyze the trend in pressure changes.

Methods: Twenty TKAs were first balanced by conventional techniques, and then femorotibial pressure was measured using the sensor. After this, the difference in pressure among different joint gaps was calculated to analyze the trend. A repeated measure of analysis of variance and a Tukey's honestly significant difference (HSD) test were used to analyze the data.

Results: The medial gap pressure was significantly increased at extension and flexion as the thickness of the sensor increased in most patients, while the lateral gap pressure changed without a specific trend. The average medial gap pressure was significantly larger than the average lateral gap pressure at both the full extension and $90^{\circ}$ flexion positions. The average extension gap pressure was larger than the average flexion gap pressure at both the medial and lateral gaps.

Conclusions: The tension of the soft tissue around the knee joint changes with the joint gap. The tension at the medial side is higher than that on the lateral side, and that of the extension position is higher than that of the flexion position. The use of the pressure sensor insert has a better auxiliary effect on the operation using the gap-balancing technique.
\end{abstract}

Keywords: Sensor; soft-tissue tension; total knee arthroplasty (TKA); femorotibial pressure

Submitted Feb 28, 2020. Accepted for publication Sep 06, 2020.

doi: 10.21037/atm-20-2044

View this article at: http://dx.doi.org/10.21037/atm-20-2044

\section{Introduction}

Total knee arthroplasty (TKA) is widely used in the treatment of patients with end-stage osteoarthritis (1). Currently, it is the most widely performed orthopedic operation in the United States $(2,3)$. The success of TKA depends on various surgical factors, such as accurate bone resection, appropriate alignment of the prosthesis, correct rotation of the femur and tibia, matching of the inherent constraint of the device with the host soft-tissue envelope, and above all, adequate soft-tissue balance (4-6). Although advances in the implant design and operating technique have contributed to the long-term success of TKA, about $20 \%$ 
of patients undergoing TKA report being dissatisfied (7). These complaints may result from complications such as pain, stiffness, or instability, all of which may be caused by unbalanced soft tissue (8-10). In order to achieve a balanced knee after surgery, the characteristics of the soft tissue needs to be clearly understood. Some scholars have reported the characteristics of the soft tissue through in vivo research, cadaver research and imaging research, but their methods of measuring soft tissue tension are generally indirect (11-13).

Soft-tissue tension has traditionally been judged according to the subjective "feeling" of experienced surgeons rather than by using an objective measure $(14,15)$. In order to measure soft-tissue tension visually, a load-sensor device was developed to measure the femorotibial contact pressures during the TKA procedure. It enables surgeons to quantify soft-tissue balance based on real-time, evidencebased data during TKA (16). Some studies report that the use of the sensor can improve the outcome of TKA (17). However, studies that evaluate the normal soft-tissue pressure and the variation trend of femorotibial pressures under different gap values using the sensor are lacking. The objective of this study was to use the sensor to analyze the trend in femorotibial pressure changes along with changes in the joint gap. We present the following article in accordance with the STROBE reporting checklist (available at http://dx.doi.org/10.21037/atm-20-2044).

\section{Methods}

We prospectively evaluated 20 patients who underwent primary TKA from July 2019 to December 2019 at our hospital's Department of Orthopedics. All patients were operated on by the same surgeon using posterior stabilized total knee prostheses (Legion Total Knee Replacement System; Smith \& Nephew, Memphis, TN, USA). The criteria for inclusion of patients in the study were the following: (I) being eligible for a primary posterior stabilized TKA, (II) being diagnosed with osteoarthritis, and (III) having a varus angle between $0^{\circ}$ to $10^{\circ}$. Patients were excluded if they had (I) a prior TKA; (II) ligament insufficiencies of the knee; (III) prior surgeries such as anterior or posterior cruciate ligament (PCL) reconstructions, posterolateral reconstructions, and/or osteotomies; (IV) a history of tibia plateau fracture; (V) range of motion (ROM) less than $90^{\circ}$; (VI) a flexion contracture of more than $20^{\circ}$; and (VII) a body mass index (BMI) over $30 \mathrm{~kg} / \mathrm{m}^{2}$ or less than $18.5 \mathrm{~kg} / \mathrm{m}^{2}$.

The patients were operated on in a supine position with one side of the thigh supported and the heel supported by a bolster, allowing for knee joint flexion. A standard medial parapatellar approach was used to expose the knee joint. The femoral side was prepared for a posterior-stabilized TKA (PS TKA) using intramedullary guidance, and the tibial side was extramedullary guided. Bone was resected in the order of the distal femur and proximal tibia.

After the bone was cut, the extension gap was evaluated using a mechanical caliper and tensioner (Smith and Nephew, Memphis, TN, USA) (Figure 1). Forces of 20, 30, and 40 pounds were each applied at the knee extension gap (Figure 2). The extension gap value (mm) was recorded, and the difference between the medial and lateral gaps (mm) was calculated according to the reading on the mechanical caliper. Then, the tensioner was removed, and the wireless pressure sensor tibial insert (iJoint, Shanghai, China) was used to measure the medial and lateral femorotibial pressures (which may reflect the soft-tissue tension of the knee joint) at the knee extension gap. Gradually, the thickness of the pressure sensor was increased by $1 \mathrm{~mm}$ at the shims, and the changes of the medial and lateral pressure values were recorded. The soft tissue was considered imbalanced if the difference between the medial and lateral gap value was over $2 \mathrm{~mm}$ when the joint gap was distracted by the mechanical caliper and tensioner using 20 pounds of force; if the soft tissue was found to be imbalanced, then a further soft-tissue release was performed until the difference was less than $2 \mathrm{~mm}$. At this time, the mechanical caliper and tensioner were again used to measure and record the values of the distracting joint gap under the force of 20,30, and 40 pounds respectively; the medial and lateral femorotibial pressures were then remeasured by the pressure sensor tibial inserts of different thicknesses. After the extension gap was balanced, the mechanical caliper, as a gap-balancing tool, was used to obtain a balanced flexion gap. The medial and lateral femorotibial pressures of the balanced flexion gap were measured and recorded by the pressure sensor tibial inserts of different thicknesses (Figures 3,4).

Femorotibial pressures were measured in 2 compartments (medial and lateral) through 2 positions (extension and $90^{\circ}$ of flexion) and 3 different thicknesses, resulting in 12 pressures that were observed and recorded per patient. Furthermore, we calculated the difference in pressure between the medial and lateral compartments (intercompartmental difference) throughout the 2 positions and 3 thicknesses.

All operation procedures and intraoperative measurements were performed by a single-joint surgeon with more than 15 years of experience. 

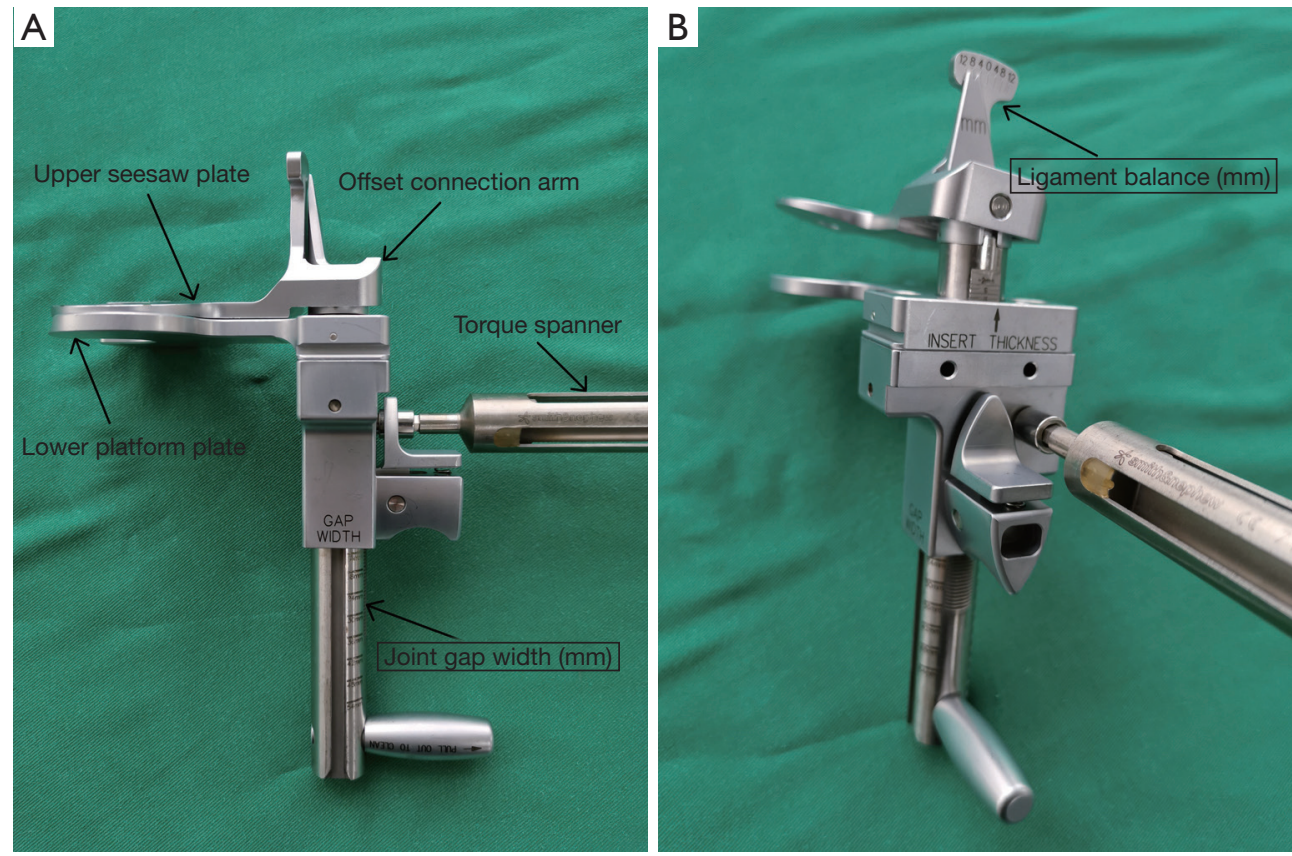

Figure $1 \mathrm{~A}$ mechanical caliper and tensioner with a torque spanner were used to distract and evaluate the joint gap during the operation. The pointer and scale on the caliper can display the difference between the medial and lateral joint gap values.

\section{Ethical statement}

The study was conducted in accordance with the Declaration of Helsinki (as revised in 2013). The study was approved by the Ethics Committee for Human Subjects of our hospital (NO. D2018084) and informed consent was taken from all the patients.

\section{Statistical analysis}

The results were analyzed with the use of the statistical packages R (The R Foundation; http://www.r-project.org; version 3.4.3) and Empower (R) (www.empowerstats.com, $\mathrm{X} \& Y$ Solutions, Inc. Boston, MA, USA). All the values are expressed as the mean \pm standard error of the mean. The joint gap pressures of different insert thicknesses and the medial and lateral gap pressures of different positions were compared using a repeated measure of analysis of variance, and a post hoc analysis was performed using Tukey's honestly significant difference (HSD) test. A P value $<0.05$ was considered statistically significant.

\section{Results}

After the data of patients meeting the exclusion criteria are

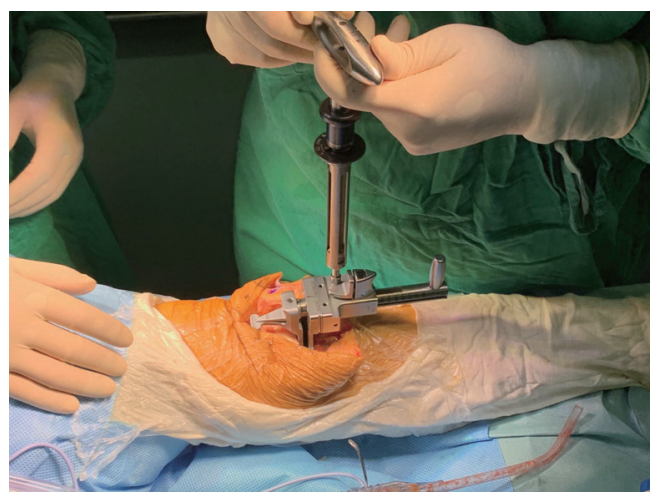

Figure 2 After the bone of the distal femur and proximal tibia was resected, we loaded 20,30, and $40 \mathrm{lb}$ of distraction force to distract the extension gap.

excluded, there were 17 female patients and 3 male patients in this study. The mean (standard deviation) age was $63.9 \pm 6.7$ years, and the mean BMI was $26.8 \pm 1.6 \mathrm{~kg} / \mathrm{m}^{2}$. The mean preoperative varus angle was $5.3^{\circ} \pm 2.3^{\circ}$.

The medial and lateral gap pressures were measured by the sensor after balancing by conventional technique. The intercompartmental loading differences of all the patients were lower than $40 \mathrm{~N}$ at the full extension position, and 5 


\section{Page 4 of 10}

of the 20 patients $(25 \%)$ had a value over $40 \mathrm{~N}$ at the $90^{\circ}$ flexion position. The average extension medial gap pressure was $67.8 \pm 15.4 \mathrm{~N}$ (ranging from 45.6 to $101.7 \mathrm{~N}$ ), the average extension lateral gap pressure was $54.6 \pm 25.4 \mathrm{~N}$ (ranging from 25.1 to $125.4 \mathrm{~N}$ ), the average flexion medial gap pressure was $50.6 \pm 27.4 \mathrm{~N}$ (ranging from 20.0 to $124.3 \mathrm{~N}$ ), and the average flexion lateral gap pressure was $45.1 \pm 25.2 \mathrm{~N}$ (ranging from 0 to $90.2 \mathrm{~N}$ ) (Table 1). After increasing the thickness of the sensor with a $1-\mathrm{mm}$ shim, the medial and lateral gap pressures increased by $75.4 \%$ and $18.1 \%$ in extension and by $54.9 \%$ and $10.9 \%$ in flexion, respectively. After adding another $1-\mathrm{mm}$ shim, the medial and lateral gap pressure increased by $42.1 \%$ and $23.4 \%$ in extension and by $48.5 \%$ and $13.8 \%$ in flexion, respectively (Figure 5). The comparison of femorotibial pressures at different positions and compartments are shown in Figures 6,7; the $\mathrm{P}$

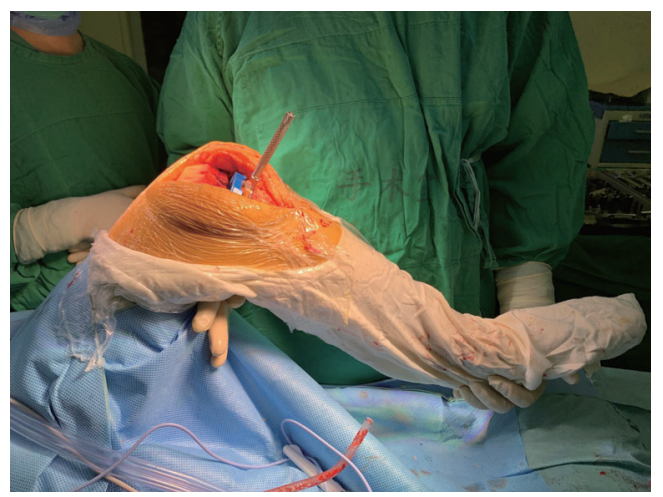

Figure 3 A wireless sensor device was used to measure the gap pressure at $90^{\circ}$ of flexion. In order to reduce the influence of gravity on the measurement results, the surgeon gave a support force to the back of the popliteal fossa and heel.

\section{Li et al. Correlation between femorotibial pressure and joint gap}

values are shown in Table 2.

\section{Discussion}

Our results found the characteristic changes in the tension of the knee joint soft tissue and showed that the use of the pressure sensor insert had a better auxiliary effect on the operation using the gap-balancing technique.

Despite the great progress in surgical technique and prosthesis design, a high proportion of patients still have unsatisfactory postoperative results due to the increased operation volume of TKA. There are many reasons for patient dissatisfaction, including postoperative pain, joint stiffness, joint instability, etc., and soft-tissue imbalance may be one of the reasons for these adverse consequences. Accurate evaluation of the knee joint for soft-tissue balance has always been an aspect of great concern for joint surgeons. Many devices have been invented to assist surgeons during the operation procedure, including a space block, scaled-force forceps, and a gap balancer (11), but these devices can only provide a qualitative assessment of soft-tissue balance. The invention and application of the sensor device provide the possibility of a quantitative evaluation of soft-tissue balance in TKA.

In order to achieve a good soft-tissue balance during the operation, we need to first determine the value of the normal knee joint soft-tissue tension. Due to the differences in individual development, muscle strength, and gait habits, the optimal tension state of knee joint soft tissue in different patients is not the same. The normal soft-tissue tension of the knee joint reported in the literature should be the absolute value of the medial and the lateral compartments and should not be more than 40 pounds. This information
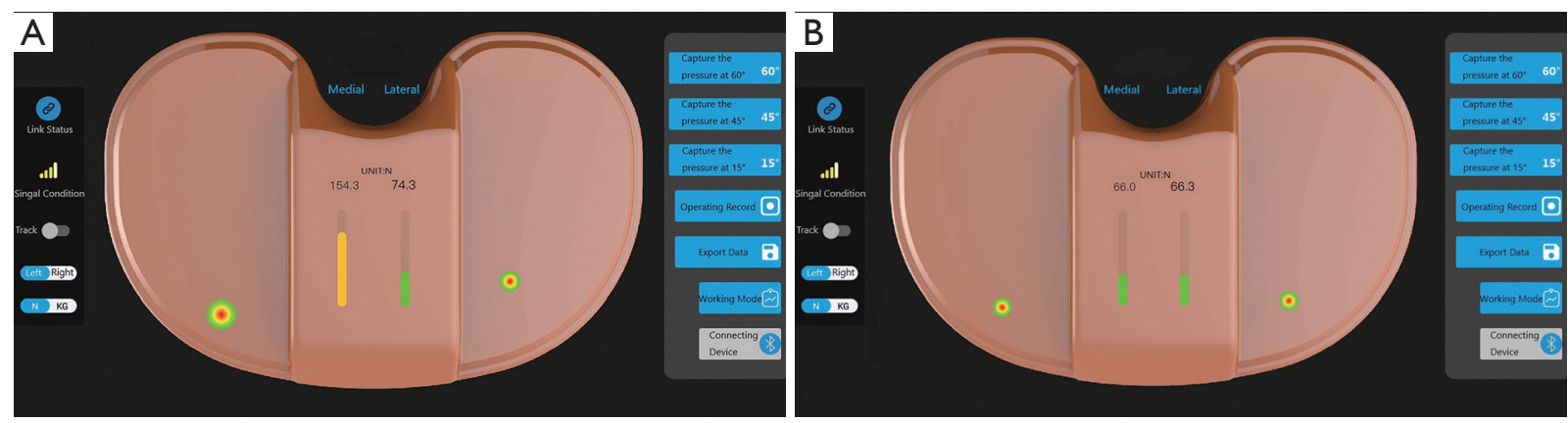

Figure 4 Graphic interfaces demonstrating the medial and lateral compartment pressure values and the pressure contact points are shown. Tight medial soft tissues causing elevated medial compartment pressure (A). Compartment pressures were more equalized after a medial soft tissue release (B). 
Table 1 Tibiofemoral pressures of different insert thicknesses

\begin{tabular}{|c|c|c|c|}
\hline Gaps & \multicolumn{3}{|c|}{ Insert thickness } \\
\hline \multicolumn{4}{|c|}{ Extension gap pressure $(\mathrm{N})$} \\
\hline Medial & $67.8 \pm 15.4$ & $118.1 \pm 33.3$ & $165.6 \pm 42.5$ \\
\hline Lateral & $54.6 \pm 25.4$ & $61.2 \pm 31.1$ & $78.5 \pm 60.0$ \\
\hline Medial & $50.6 \pm 27.4$ & $77.5 \pm 61.9$ & $102.2 \pm 78.4$ \\
\hline Lateral & $45.1 \pm 25.2$ & $48.8 \pm 31.5$ & $56.9 \pm 39.4$ \\
\hline
\end{tabular}

Values are shown as mean \pm SEM $(\mathrm{N})$. Flexion position refers to a flexion of $90^{\circ}$; extension position refers to an extension of $0^{\circ}$. SEM, standard error of the mean.
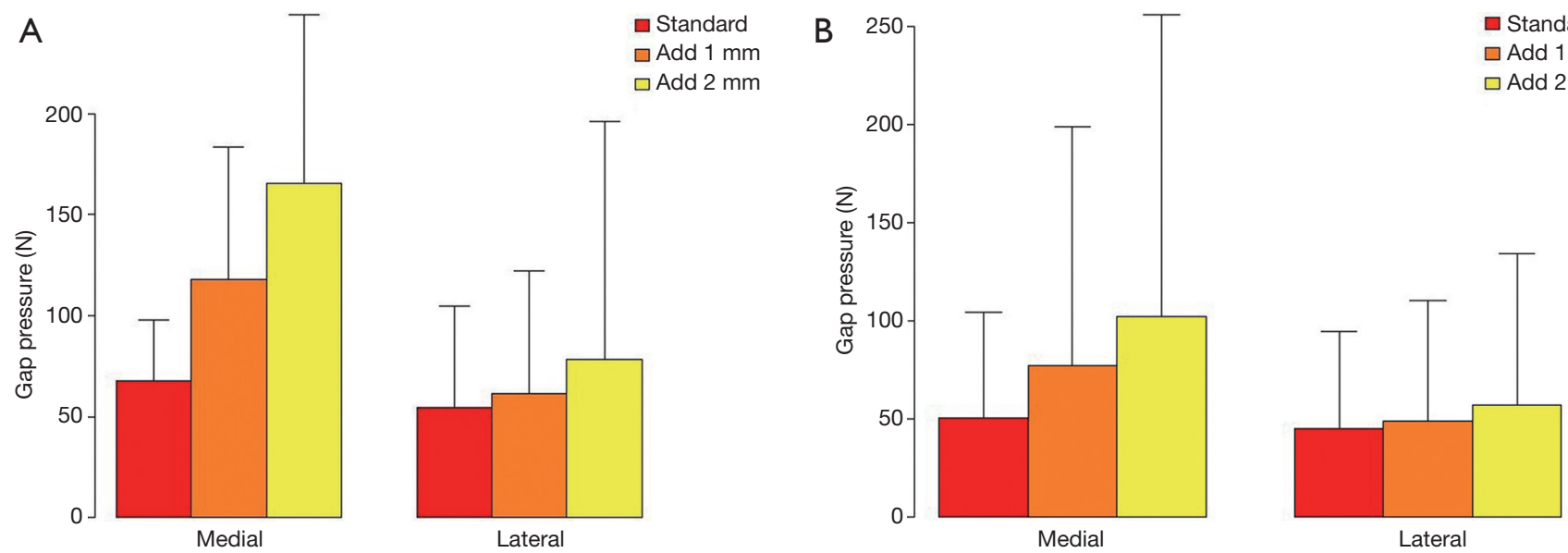

Figure 5 Medial and lateral compartment pressures of different insert thicknesses. Compartment pressures increased as insert thickness increased. (A) Full extension position; (B) $90^{\circ}$ flexion position.

was based on biomechanical research on condylar pressures in a passive state (18). Balanced knee joint soft tissue is defined as the pressure difference between the medial and lateral compartments and should be less than 15 pounds. The decision to choose $15 \mathrm{lb}$ as the upper limit for the balance was made based on a study that Gustke et al. reported. In the study, a group of experienced joint surgeons using intraoperative navigation to quantify $2-\mathrm{mm}$ openings of the knee joint gap with varus or valgus force, found significant drop-offs of the postoperative patient-reported outcome scores in patients with intercompartmental loading differences exceeding $20 \mathrm{lb}$ (17). Therefore, in our study, we selected the balanced soft-tissue tension as the absolute value of the medial and the lateral compartment pressure in the range of 60 to $135 \mathrm{~N}$, with the pressure difference between the medial and the lateral compartment is less than $40 \mathrm{~N}$. Quantitative measurement and verification were performed by the sensor device during operation.

In our study, all patients obtained the rotational alignment of the femoral component with the method of gap-balancing. The gap-balancing technique is characterized by first performing appropriate soft-tissue release before osteotomy to calibrate the tension of the medial and lateral soft tissues during flexion, then determining the angle of posterior condyle osteotomy according to the balanced state of the medial and lateral soft-tissue tension, so as to obtain a rectangular flexion gap with the same size as that of the extension gap $(19,20)$. Compared with the resection measurement technique using the axis of anatomical markers as a reference, the gap-balancing technique is more dependent on accurate soft-tissue balance; therefore, it is not necessary to worry about the abrasion or dysplasia 

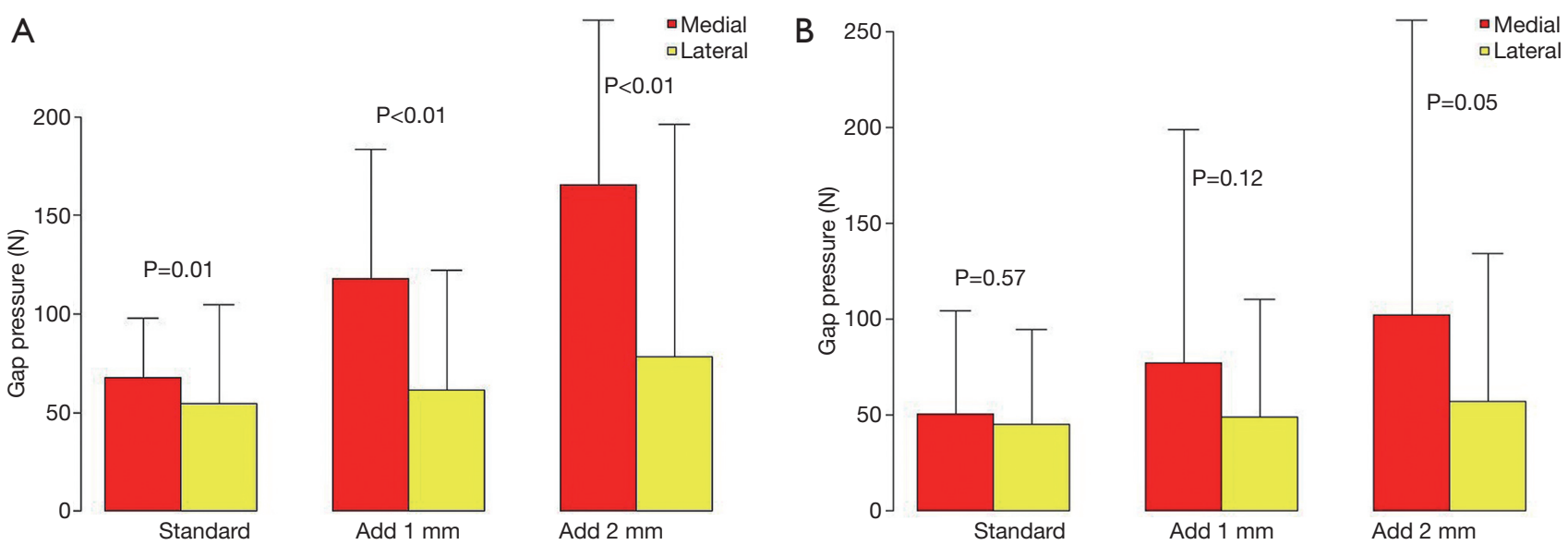

Figure 6 Comparison of medial and lateral compartment pressures of different insert thicknesses. (A) Full extension position ( $\mathrm{P}<0.05)$; the medial compartment pressures were significantly higher than those of the lateral compartment; (B) $90^{\circ}$ flexion position $(\mathrm{P}>0.05)$; the statistical difference was not significant.
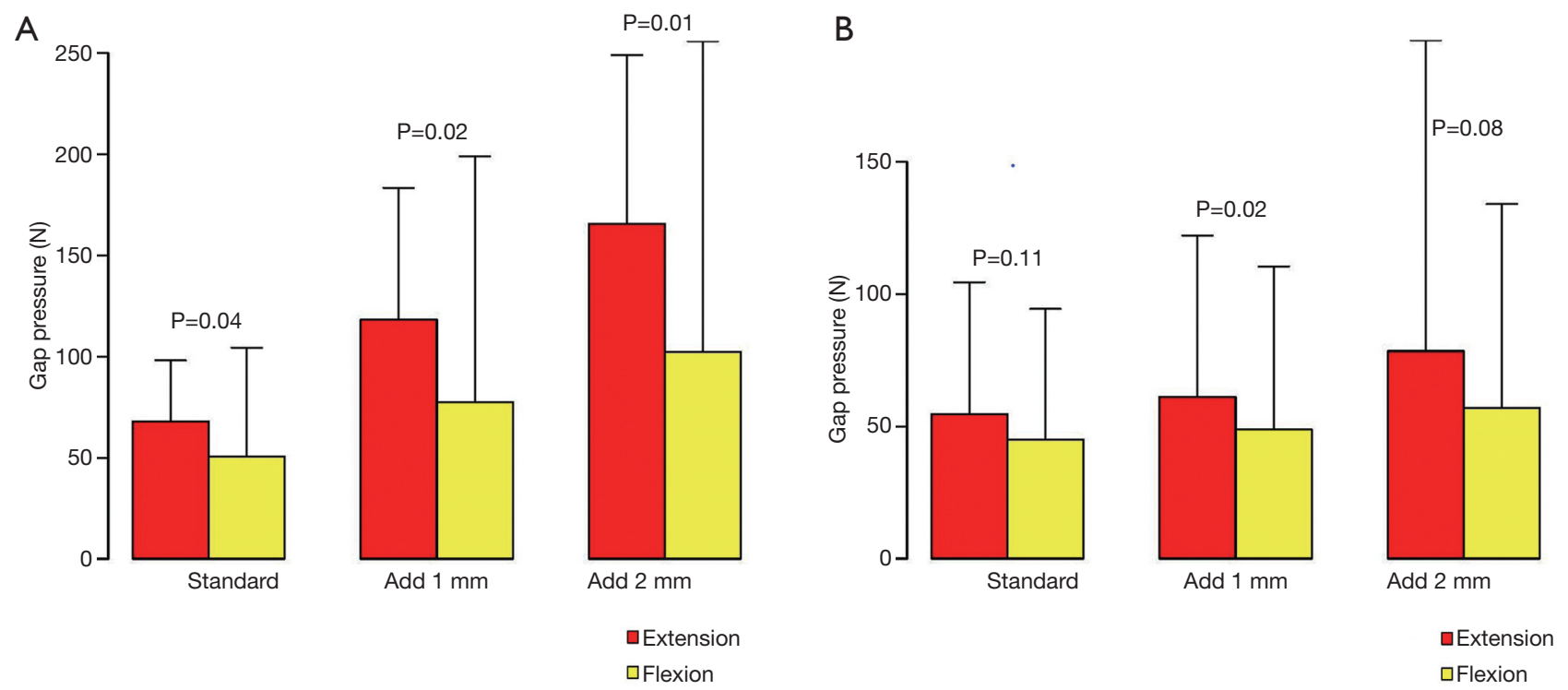

Figure 7 Comparison of extension and flexion gap pressures of different insert thicknesses. (A) In the medial compartment $(\mathrm{P}<0.05)$, the extension gap pressures were significantly higher than those of the flexion gap; (B) lateral compartment $(\mathrm{P}>0.05)$; the statistical difference was not significant.

of the posterior femoral condyle and trochlear groove, or about the problem of inaccurate positioning when palpating the medial epicondylar groove due to soft-tissue coverage or other reasons. However, the differences in the flexion gap tension will directly affect the placement of the final prosthesis. We have yet to determine the flexion gap under large or small tension conditions; therefore, it is important to understand the trend of flexion gap tension changes for obtaining accurate flexion gaps. In the operative procedure of this study, we used the mechanical caliper and tensioner to obtain a flexion gap with the same size as the extension gap; then, the pressure sensor was used to measure the soft-tissue tension of the medial and lateral compartments. We found that the extension gap pressure was larger than the flexion gap pressure, although they were of the same size. From our experience, we think that the gap-balancing 
Table $2 \mathrm{P}$ values of the comparison of tibiofemoral pressures at different positions and compartments

\begin{tabular}{|c|c|c|c|}
\hline Positions & \multicolumn{3}{|c|}{ Insert thickness } \\
\hline \multicolumn{4}{|l|}{ Extension } \\
\hline Medial vs. lateral & $0.01^{*}$ & $<0.01^{*}$ & $<0.01^{*}$ \\
\hline \multicolumn{4}{|l|}{ Flexion } \\
\hline \multicolumn{4}{|l|}{ Medial } \\
\hline Extension vs. flexion & $0.04^{*}$ & $0.02^{*}$ & $0.01^{*}$ \\
\hline \multicolumn{4}{|l|}{ Lateral } \\
\hline Extension vs. flexion & 0.11 & $0.02^{*}$ & 0.08 \\
\hline
\end{tabular}

A P value $<0.05$ was considered statistically significant $\left(^{*}\right)$. The Tukey's honestly significant difference (HSD) test was performed to compare the pairs.

technique is more conducive for achieving flexion gap balance, provided an appropriate gap tension is present. The sensor device can measure the gap pressure accurately and quantitatively making it a better auxiliary function for operations using the gap-balancing technique. Cho et al. reported the proportion of balanced knees after initial bony resection in 84 patients who underwent TKA using the sensor device and found that modified gap-balancing TKAs showed a significantly higher proportion of balanced knees than measured resection TKAs (21). This also confirms our point of view.

In our study, we observed that with the increase of the thickness of the sensor, whether in the fully extended position or in the $90^{\circ}$ flexion position, the pressure of the medial and lateral compartments of the knee joint will increase gradually in most cases, and the pressure of the medial compartment will generally be higher than that of the lateral compartment. These findings indicate that the soft tissue around the knee joint has a certain level of compliance. The increase in the knee joint gap will directly lead to an increase of medial and lateral soft-tissue tension. When the medial and lateral gap values are equal, the medial soft-tissue tension of the knee joint is higher than the lateral soft-tissue tension, which suggests that the stiffness of the medial soft tissue of the knee joint is higher. Schirm et al. (12) conducted a fresh-frozen cadaveric knee joint experiment and found that increasing the implantation tightness by $2 \mathrm{~mm}$ increased the compressive force at $0^{\circ}$ by $54 \%$ to $131 \%$ in all models tested, and these effects were particularly noted in the PCL-retaining and mobile- bearing prostheses. Decreasing the implantation tightness by $2 \mathrm{~mm}$ at $0^{\circ}$ led to a decrease in the compressive force by $33 \%$ to $84 \%$. Nagai et al. (22) tested 78 patients with genu varum who underwent TKA and found that under the same tension of the medial and lateral gap, the opening degree of the medial gap was smaller than that of the lateral gap, and the stiffness of the medial soft tissue was higher than that of the lateral soft tissue, which is similar to the conclusion of our study. This phenomenon may be due to the following mechanisms: on the one hand, most of the patients with osteoarthritis of the knee joint had varus deformities before the operation, causing the medial soft tissue to contract and the lateral soft tissue to be lax. On the other hand, some researchers observed varus and valgus joint soft-tissue laxity in the flexion state of the knee joint in normal people through magnetic resonance imaging (MRI) and found that the lateral gap was significantly larger than the medial gap. There is a certain degree of physiological lateral laxity in normal knee joints (13). In our study, we quantitatively measured the medial and lateral compartment stiffness. The experimental data also confirmed that the soft-tissue stiffness of the medial compartment was higher than that of the lateral compartment in the fully extended or $90^{\circ}$ flexion positions.

However, we also found that the increase of the medial and lateral compartment pressure is not always in a synchronous state in some cases, as in when the thickness of the sensor increases to a certain extent. When this happens, the lateral side of the sensor will be warped and has less contact with the lateral tibia and femoral 
Page 8 of 10

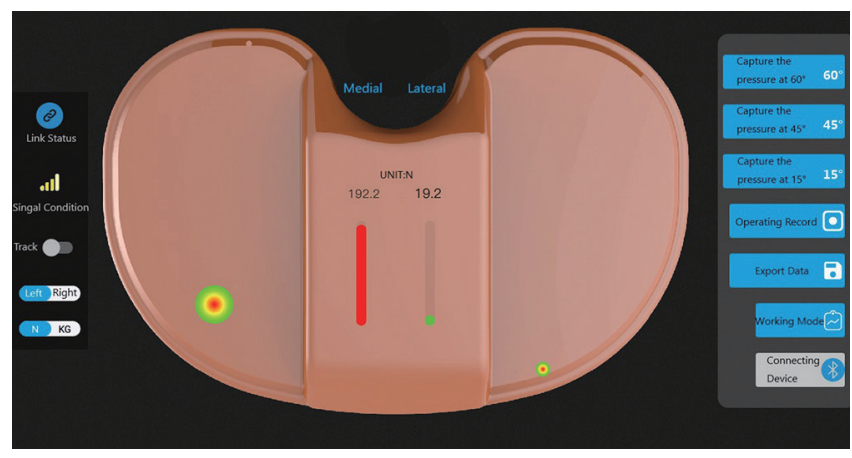

Figure 8 The excessive pressure of the medial compartment caused the lateral side of the sensor to be warped and have less contact with the lateral tibia and femoral osteotomy surfaces, with the lateral compartment pressure decreasing.

osteotomy surfaces, which is called "lift-off" (Figure 8). At this time, the pressure value of the lateral gap, in some cases, decreases. Sometimes, the lateral side of the sensor is completely contactless, and the pressure sensor reading is 0 . This may be due to the excessive pressure of the medial compartment. Kanto's study found that with the increase of the joint gap distraction force, the varus ligament balance significantly increased. These findings indicate that the lateral compartment gap tends to be larger than the medial compartment gap as the joint gap distraction force increases (22). In the procedure of operation with the method of gap-balancing, the key point of the operation is to obtain an equal and parallel rectangular joint gap in the extension and flexion position by osteotomy and soft-tissue release. After obtaining the ideal joint gap and choosing the appropriate type of prosthesis, the thickness of the polyethylene insert will directly affect the balanced state of the joint. Placing the polyethylene insert is equivalent to distracting the joint gap. When the thickness of the insert is initially small, it will not significantly affect the rectangular shape of the joint gap or the balance of surrounding soft tissue due to its small distraction force on the joint gap. However, using too thin of an insert may lead to joint laxity and poor stability after the operation, which is associated with patient dissatisfaction and the risk of implant failure in the mid- to long-term $(19,23,24)$. In contrast, tighter inserts can improve joint stability $(25,26)$ but can cause pain, discomfort, and functional deficits (23), including reduced ROM, polyethylene wear, and prosthesis loosening $(27,28)$. With the increase of the thickness of the insert, the distraction force increases gradually, and the joint gap will gradually become trapezoidal, thus, losing the original
Li et al. Correlation between femorotibial pressure and joint gap

balanced state. At present, the design of the knee prosthesis tends to be individualized and refined. The thickness of the polyethylene insert can be increased by $1 \mathrm{~mm}$. An accurate prosthesis design provides more options for joint surgeons but also requires a more accurate assessment of the tension of the knee joint soft tissue. Therefore, the realtime, quantitative assessment of soft-tissue tension provided by the sensor device during operation can provide a more informed basis for surgeons to select the specifications of the polyethylene insert. The clinical significance of refined polyethylene insert designs is paramount and of great benefit to the patients.

Although our study yielded some important insights, a few limitations should be addressed. First, in order to reduce the confounding factors that may affect the experimental results, all the patients underwent PS TKA in our study, and thus the data for cruciate-retaining TKA (CR TKA) lacks due to the retention of the PCL, the preservation of PCL will definitely have an effect on tibiofemoral pressure, we will study it in the future research. Second, the sample size was relatively small. The small sample size reduces the chance of acquiring genuine results and the possibility of statistically significant results reflecting the true effect. Third, we only measured the femorotibial pressures at 2 positions (full extension and $90^{\circ}$ flexion), and there was a lack of data from other flexion angles for the knee joint ROM. Fourth, the relationship between our definition of soft-tissue balance and patients' short-term rehabilitation, long-term functional outcomes, and survival rate is not clear and needs further follow-up research.

\section{Conclusions}

Our study preliminarily explored the trend of the change in soft-tissue tension around the knee joint with respect to the size of the joint gap. We confirmed that the tension of the medial soft tissue of the knee joint was higher than that of the lateral soft tissue in the extension and flexion positions, and the tension of the medial soft tissue in the extension position was higher than that of the flexion position. This finding indicates that it is important to choose the appropriate size of the joint gap during the operation for soft-tissue balance, especially when using the gap-balancing technique. It can also guide the selection of the thickness of the polyethylene insert when the final prosthesis is placed. The pressure sensor insert also has a good auxiliary effect on the operation using the gap-balancing technique. This can effectively improve the accuracy of soft-tissue tension 
measurements.

\section{Acknowledgments}

The authors wish to thank Dr. Jiang Liya, Dr. Yang Xiaosong, Dr. Li Zhehuang, and Dr. Chen Zhen for their assistance in the preparation of this manuscript. The authors would like to thank Ms. Wang Fengying for her help in data collection and collation. The authors would like to thank AJE (www.aje.com) for English language editing. Funding: None.

\section{Footnote}

Reporting Checklist: The authors have completed the STROBE reporting checklist. Available at http://dx.doi. org/10.21037/atm-20-2044

Data Sharing Statement: Available at http://dx.doi. org/10.21037/atm-20-2044

Peer Review File: Available at http://dx.doi.org/10.21037/ atm-20-2044

Conflicts of Interest: All authors have completed the ICMJE uniform disclosure form (available at http://dx.doi. org/10.21037/atm-20-2044). The authors have no conflicts of interest to declare.

Ethical Statement: The authors are accountable for all aspects of the work in ensuring that questions related to the accuracy or integrity of any part of the work are appropriately investigated and resolved. The protocol for the research project has been approved by the Ethics Committee for Human Subjects of the Peking University Third Hospital (NO. D2018084). The study conformed to the provisions of the Declaration of Helsinki (as revised in 2013). Informed consent was provided by all participating individuals.

Open Access Statement: This is an Open Access article distributed in accordance with the Creative Commons Attribution-NonCommercial-NoDerivs 4.0 International License (CC BY-NC-ND 4.0), which permits the noncommercial replication and distribution of the article with the strict proviso that no changes or edits are made and the original work is properly cited (including links to both the formal publication through the relevant DOI and the license).
See: https://creativecommons.org/licenses/by-nc-nd/4.0/.

\section{References}

1. Kurtz S, Ong K, Lau E, et al. Projections of primary and revision hip and knee arthroplasty in the United States from 2005 to 2030. J Bone Joint Surg Am 2007;89:780-5.

2. Mulhall KJ, Ghomrawi HM, Scully S, et al. Current etiologies and modes of failure in total knee arthroplasty revision. Clin Orthop Relat Res 2006;446:45-50.

3. Gustke K. Use of smart trials for soft-tissue balancing in total knee replacement surgery. J Bone Joint Surg Br 2012;94:147-50.

4. Freisinger GM, Hutter EE, Lewis J, et al. Relationships between varus-valgus laxity of the severely osteoarthritic knee and gait, instability, clinical performance, and function. J Orthop Res 2017;35:1644-52.

5. Smeets K, Bellemans J, Scheys L, et al. Mechanical analysis of extra-articular knee ligaments. Part two: tendon grafts used for knee ligament reconstruction. Knee 2017;24:957-64.

6. Bozic KJ, Kurtz SM, Lau E, et al. The epidemiology of revision total knee arthroplasty in the United States. Clin Orthop Relat Res 2010;468:45-51.

7. Gunaratne R, Pratt DN, Banda J, et al. Patient Dissatisfaction Following Total Knee Arthroplasty: A Systematic Review of the Literature. J Arthroplasty 2017;32:3854-60.

8. Fehring TK, Odum S, Griffin WL, et al. Early failures in total knee arthroplasty. Clin Orthop Relat Res 2001;(392):315-8.

9. Sharkey PF, Hozack WJ, Rothman RH, et al. Why Are Total Knee Arthroplasties Failing Today? J Arthroplasty 2014;29:1774-8.

10. Kuster MS, Stachowiak G. Factors affecting polyethylene wear in total knee arthroplasty. Orthopedics 2002;25:s235-42.

11. Asano H, Hoshino A, Wilton TJ. Soft-tissue tension total knee arthroplasty. J Arthroplasty 2004;19:558-61.

12. Schirm AC, Jeffcote BO, Nicholls RL, et al. Sensitivity of knee soft-tissues to surgical technique in total knee arthroplasty. Knee 2011;18:180-4.

13. Tokuhara Y, Kadoya Y, Nakagawa S, et al. The flexion gap in normal knees. An MRI study. J Bone Joint Surg Br 2004;86:1133-6.

14. Bellemans J, Vandenneucker H, Van Lauwe J, et al. New surgical technique for medial collateral ligament balancing. J Arthroplasty 2010;25:1151-6. 


\section{Page 10 of 10}

15. Boldt JG, Stiehl J, Hodler J, et al. Femoral component rotation and arthrofibrosis following mobile-bearing total knee arthroplasty. Int Orthop 2006;30:420-5.

16. Gustke KA. Soft-tissue and alignment correction: the use of smart trials in total knee replacement. Bone Joint J 2014;96-B:78-83.

17. Gustke KA, Golladay GJ, Roche MW, et al. A new method for defining balance: promising short-term clinical outcomes of sensor guided TKA. J Arthroplasty 2014;29:955-60.

18. Walker PS, Meere PA, Bell CP. Effects of surgical variables in balancing of total knee replacements using an instrumented tibial trial. Knee 2014;21:156-61.

19. Griffin FM, Insall JN, Scuderi GR. Accuracy of soft tissue balancing in total knee arthroplasty. J Arthroplasty 2000;15:970-3.

20. Dennis DA, Komistek RD, Kim RH, et al. Gap balancing versus measured resection technique for total knee arthroplasty. Clin Orthop Relat Res 2010;468:102-7.

21. Cho KJ, Seon JK, Jang WY, et al. Objective quantification of ligament balancing using VERASENSE in measured resection and modified gap balance total knee arthroplasty. BMC Musculoskelet Disord 2018;19:266.

Cite this article as: Li X, Cai H, Yu Z, Li Z, Zhang K, Tian H, Liu Z. Correlation between femorotibial pressure and joint gap in osteoarthritis patients with varus deformity: an intraoperative measurement using sensor device in primary posteriorstabilized total knee arthroplasty. Ann Transl Med 2020;8(21):1387. doi: 10.21037/atm-20-2044
Li et al. Correlation between femorotibial pressure and joint gap

22. Nagai K, Muratsu H, Matsumoto T, et al. Soft tissue balance changes depending on joint distraction force in total knee arthroplasty. J Arthroplasty 2014;29:520-4.

23. Kuster MS, Bitschnau B, Votruba T. Influence of collateral ligament laxity on patient satisfaction after total knee arthroplasty: a comparative bilateral study. Arch Orthop Trauma Surg 2004;124:415-7.

24. Ridgeway S, Moskal JT. Early instability with mobilebearing total knee arthroplasty: a series of 25 cases. J Arthroplasty 2004;19:686-93.

25. Dejour D, Deschamps G, Garotta L, et al. Laxity in posterior cruciate sparing and posterior stabilized total knee prostheses. Clin Orthop Relat Res 1999;(364):182-93.

26. Laskin RS, Beksac B. Stiffness after total knee arthroplasty. J Arthroplasty 2004;19:41-6.

27. Swany MR, Scott RD. Posterior polyethylene wear in posterior cruciate ligament retaining total knee arthroplasty. A case study. J Arthroplasty 1993;8:439-46.

28. Wasielewski RC, Galante JO, Leighty RM, et al. Wear patterns on retrieved polyethylene tibial inserts and their relationship to technical considerations during total knee arthroplasty. Clin Orthop Relat Res 1994;299:31-43. 